\title{
O Brasil que se divisa em Gilberto Freyre
}

\author{
Brazil as glimpsed in Gilberto Freyre
}

\author{
André Botelho \\ Professor do Programa \\ de Pós-Graduação em Sociologia e Antropologia da \\ Universidade Federal do Rio de Janeiro \\ Rua Montecaseros, 38/202 \\ 25685-001 Petrópolis - RJ Brasil \\ andrebotelho@digirotas.com.br
}

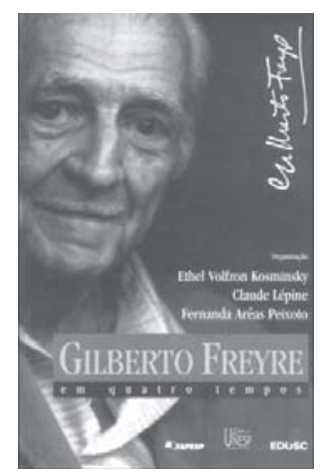

Ethel Volfzon Kosminsky, Claude Lépine e Fernanda Arêas Peixoto (orgs.). Gilberto Freyre em quatro tempos

São Paulo, Edusc, 2003, 380 p.
Z sta coletânea reúne 22 trabalhos originalmente apresentados na ¿ VII Jornada de Ciências Sociais da Faculdade de Filosofia e Ciências da Unesp-Marília, em novembro de 2000. Cobrindo diferentes áreas do conhecimento, o livro está organizado em cinco partes: Depoimentos, Fontes e afinidades do pensamento de Gilberto Freyre, Espaços e identidades, Aspectos da cultura e da sociedade brasileira e Regionalismo e modernismo.

Em cada uma delas encontram-se trabalhos que, como estimam justamente as organizadoras, têm "como objetivo repensar a obra de Gilberto Freyre e, no caso de alguns, contribuir para o desenvolvimento dos temas por ele tratados" (p. 7). Isso, pode-se assinalar, a exemplo dos artigos de Edson Nery da Fonseca e Thomas Skidmore, sobre a recepção da obra de Freyre; dos de Maria Lúcia Pallares-Burke e Regina Aída Crespo, sobre as matrizes intelectuais de que é devedora; dos de Eni de Mesquita Samara e Claude Lépine, sobre alguns dos seus temas centrais, como, respectivamente, família e alimentação; do de Lúcia Lippi Oliveira, sobre livros menos freqüentados pelos analistas como Ordem e progresso (1959); ou ainda dos de Antonio Dimas e Guillermo Giucci, sobre os contextos modernista e regionalista de sua gestação.

Por isso a leitura do conjunto de Gilberto Freyre em quatro tempos sugere a complexidade do pensamento do sociólogo pernambucano, e contribui para o entendimento das suas idéias, para a reavaliação da sua influência intelectual, social e política e para pensar a sociedade brasileira como um todo. Ganhamos particularmente os pesquisadores da área de pensamento social brasileiro, dada inclusive a multiplicidade de abordagens metodológicas presentes no livro, que vão da história das idéias à história intelectual, da esfera da produção à da recepção das idéias, passando, em alguns casos, por procedimentos tipicamente hermenêuticos, lingüísticos ou contextuais de análise das idéias. Destaco, para discussão, dois trabalhos representativos do que se está sugerindo: 'A atualidade de Gilberto Freyre', de Jessé Souza, e 'Casa grande e terra grande, sertões e senzala: a sedução das origens', de Glaucia Villas Bôas. 
Procurando articular as problemáticas da modernização e da cidadania no Brasil, Jessé Souza persegue as conseqüências sociais e políticas contemporâneas das idéias de Gilberto Freyre, em cuja obra vê "as bases para um ambicioso projeto de visão da formação social brasileira" marcado pela idéia de "singularidade" dessa formação (p. 68). Para tanto, propõe como estratégia ao mesmo tempo recuperar o que chama de "conteúdo latente da obra gilbertiana" (p. 65) e "usar Freyre contra ele próprio" (p. 68). Retoma, então, as teses da sociedade colonial brasileira como uma sociedade sado-masoquista, de Casa-grande $\mathcal{E}$ senzala (1933), e da constituição da modernidade brasileira, sob a forma peculiar de uma europeização que atinge o país a partir do início do século XIX, de Sobrados e mucambos (1936).

A tese da sociedade sado-masoquista refere-se, de um lado, ao estatuto particular da escravidão no Brasil, designada por Freyre de "escravidão muçulmana"; de outro, à formação social peculiar a ela associada. A escravidão muçulmana, argumenta Souza, constitui uma “astuciosa estratégia de domínio (...) na medida em que vincula o acesso a bens materiais e ideais muito concretos à identificação do dominado com os valores do opressor" (p. 69). Implicando subordinação e reprodução social do que chama de "baixa auto-estima nos grupos dominados", essa estratégia abre, contudo, possibilidade efetiva e real de diferenciação social e mobilidade. Entendendo, portanto, o sadomasoquismo como "essa assimilação da vontade externa como se fosse própria, assimilação essa socialmente condicionada e que mata no nascedouro a própria auto-representação do dominado como um ser independente e autônomo" (grifos do autor no original, p. 71), Jessé Souza sugere sua permanência condicionante, e não meramente residual, no Brasil que se moderniza sob o impacto de uma Europa individualista e burguesa, diferente daquela 'mourisca' do nosso colonizador.

Contrapondo-se ao que chama de "interpretação dominante" do processo de reeuropeização descrito por Gilberto Freyre, segundo a qual esse processo de mudança social teria um "caráter superficial, epidérmico, imitativo", Souza propõe uma leitura alternativa de Sobrados e mucambos que permitiria evidenciar que, para Freyre, o 'personalismo' antes dominante, é ferido de morte com a reeuropeização do Brasil. Afinal, lembra, "o que nos chega de navio a partir de 1808 não são apenas idéias e mercadorias exóticas (...) nos chegam as duas instituições mais importantes da sociedade moderna: Estado racional e mercado capitalista" (p. 73). No Brasil, contudo, essas duas instituições não lograram homogeneizar as condições e oportunidades sociais, já que a decadência da economia e da sociedade escravocrata "vai expulsar para a margem do sistema toda uma legião de inadaptados ao novo sistema vencedor. São eles que vão constituir nossos párias urbanos e rurais desde então" (p. 79). Concluindo o artigo, Jessé Souza defende, então, o resgate "moral e simbólico dos nossos miseráveis" numa terceira instituição que, ao lado do Estado e do mercado, é concomitante da modernidade: a esfera pública. Esta, sugere, é a condição para que "nossa modernização se complete para além do dado instrumental formal da constituição de Estado e mercado e passe a refletir sobre si própria incorporando os excluídos como sujeitos" (p. 81). 
Glaucia Villas Bôas, por sua vez, discute o que chama de "mito da ambigüidade do brasileiro" em relação à modernidade. Empregando uma perspectiva comparativa de autores ainda pouco usual na área, aproxima Gilberto Freyre e Euclides da Cunha, sugerindo que as idéias desses autores operaram tanto no sentido cognitivo, da compreensão da formação social brasileira, quanto no normativo, do desejo de intervir nos rumos de seu desenvolvimento. Nesse processo, argumenta, as representações do Brasil formuladas por esses autores não apenas identificaram grupos e movimentos, como pautaram normas de conduta e projetos de alcance político. No caso de Freyre, sugere que suas idéias deram corpo a um "modelo do Brasil da harmonia autoritária", segundo o qual "os conflitos são superados pela força de um convívio social harmônico que o ethos brasileiro se encarrega de restaurar a cada dia, equilibrando antagonismos e diferenças". Ao passo que as idéias de Euclides da Cunha teriam dado corpo a um "modelo do Brasil do eterno dilema" (p. 131).

Apesar de diferenças substantivas, como por exemplo, a busca e a ênfase na continuidade, harmonia e numa representação positiva da cultura brasileira, no caso de Casa-grande E senzala, ou na descontinuidade, conflito e numa representação negativa da cultura brasileira, no caso de Os sertões, ambas as interpretações do Brasil, argumenta a autora, operariam com a lógica da cultura e com a crença na afinidade de origem comum, manifesta na noção conservadora de temporalidade relativa às origens da sociedade. É isso que permite construir uma noção de ethos brasileiro como "maneira peculiar e única de ser socialmente, que ora se conforma ora se confronta com os desígnios da construção de uma sociedade moderna" (p. 120).

Para demostrar o argumento, Villas Bôas formula um par de distinções teóricas igualmente pouco usuais. A primeira distinção, que apenas se explicita ao final do texto, diz respeito à própria mudança de abordagem sobre as possibilidades da modernidade no Brasil operada pela sociologia dos anos 1950, a qual legitimou uma reflexão de caráter universalista evidenciando que, entre nós, entrelaçavam-se formas de conduta tradicionais e modernas. Assim, argumenta a autora, se com a sociologia permaneciam em pauta as questões da ambigüidade brasileira face ao moderno, esta não dizia mais respeito a "uma suposta história original de todos os brasileiros", mas referia-se antes a "relações sociais inerentes aos processos de mudança" (p. 132) numa sociedade de classes sob o domínio de uma ordem democrática, secularizada e competitiva.

Com base nessa observação de 'longa duração' das reflexões sobre as possibilidades da modernidade no país, Villas Bôas faz uma segunda distinção: entre "construção de nação" e "construção de sociedade" como problemáticas diferentes e com alcances teóricos variados. Para a autora, tanto Gilberto Freyre quanto Euclides da Cunha, ao contrário da sociologia dos anos 1950, operam suas interpretações a partir do primeiro paradigma, o da nação, que permite a construção de uma "identidade nacional", mas não de uma "sociedade moderna". "Em ambas as obras, Os sertões e Casa-Grande E Senzala, a história dos primórdios é positiva, pois não foram concebidas com base em um 
projeto de futuro cuja consumação exige a liquidação do passado, ao contrário, os dois livros parecem manter e guardar, seja através da memória do conflito, seja através da reatualização constante dos valores da casa-grande, aquilo que reúne e identifica os brasileiros"' (p. 129-130).

É essa indistinção entre nação e sociedade, sugere Villas Bôas, que concorre para a criação e manutenção do que chama de "mito da ambigüidade do brasileiro, ora bem-sucedida, ora mal sucedida, no seu anseio de construir a modernidade" (p. 116). Todo o problema, argumenta, é que essa indistinção não se detém nas páginas das obras de interpretação do Brasil, mas ultrapassa-as atingindo as próprias análises dessas obras. Glaucia Villas Bôas está, portanto, chamando a atenção para os problemas teóricos acarretados pela indistinção entre método e objeto naquilo que chama de "política de interpretação das interpretações do Brasil". "Nela confundem-se os valores de uma sociedade tradicional - do ponto de vista do paradigma sociológico - com o ethos brasileiro, identificando os supostos valores e qualidades dos brasileiros com os valores próprios de uma ordem social tradicional" (p. 119).

Mais do que ilustrar controvérsias que, atestando a importância da obra de Gilberto Freyre para a compreensão da sociedade brasileira, certamente prosseguirão entre nós, o esboço precedente sugere várias possibilidades comparativas. Limito-me, no entanto, a apontar apenas uma sugestão de ordem metodológica. Ambos os trabalhos pretendem oferecer uma visão de conjunto das idéias de Gilberto Freyre integrada à dinâmica da modernização e da modernidade na sociedade brasileira. E mesmo que guardem certa semelhança no ponto de partida, marcado pela tese weberiana sobre a importância dos valores e idéias na conformação da conduta social, os trabalhos seguem meios distintos, a despeito da qualidade óbvia de ambos, para um diálogo sobre o 'sentido' atual da obra de Gilberto Freyre.

No caso de Jessé Souza, como a ênfase metodológica recai sobre as instituições que reproduzem idéias e valores na "vida cotidiana" ou "no mundo concreto" (p. 74), retoma a questão clássica dos limites decorrentes do legado escravocrata ao desenvolvimento de uma sociedade democrática e igualitária no Brasil - ainda que não explicite, nessa retomada, o diálogo com outros trabalhos dedicados ao tema. Para Souza, ao contrário de Freyre, o legado escravocrata parece representar o risco ou uma possibilidade real de que a modernização não chegue a se constituir exatamente em modernidade entre nós. Assim, no desafio lançado ao final do texto, o da constituição de uma 'esfera pública' no Brasil, pulsa, de certa maneira, a concepção de que a modernidade tem os seus pré-requisitos universais e que eles representam a condição da sua efetivação em diferentes contextos históricos particulares.

No caso de Glaucia Villas Bôas, a idéia de 'ambigüidade' da modernidade brasileira é questionada, de um lado, pela sugestão de que em Freyre a preocupação central diz respeito à nação e não à sociedade; de outro, pela constatação de que os aspectos socioculturais de que é composta a idéia de ethos do brasileiro, como criatura do passado, tende a diluir a percepção da ação de valores e práticas sociais próprias à lógica moderna na configuração da sociedade brasileira e na conduta 
social dos, por assim dizer, brasileiros. Por isso, para Villas Bôas, a noção de temporalidade regente da interpretação freyreana desnuda o sentido normativo das idéias do autor. Assim, associada à sua tese central de que os processos de mudança social se fariam acompanhar no Brasil pela acomodação, os tempos não se excluem mutuamente na obra do sociólogo pernambucano, pois a liquidação do passado e do seu legado social não representariam condição para a consumação de um projeto de futuro para uma coletividade cuja coesão social, em verdade, permaneceria no 'tempo de origem' revivido e atualizado cotidianamente nas relações sociais e nas narrativas sobre ele.

Em ambos os trabalhos encontram-se, portanto, sugestões teóricas igualmente instigantes sobre o problema sociológico relativo à sobrevivência das estruturas e atitudes sociais e às condições específicas que as criaram. Permitem, cada um a seu modo, avançar na discussão sobre o estatuto sociológico das idéias como forças sociais e, nesse sentido, reconhecer que, como o conflito entre solidariedades 'tradicionais' e 'modernas' permanece como questão social, a atualização ou recusa do legado do passado é sempre fruto também de negociações e escolhas com 'sentido' político. Assim, logram enfrentar desafios centrais da área de pensamento social que justificam, num plano, não apenas a validade da discussão da obra de Gilberto Freyre, como da própria pesquisa da tradição intelectual brasileira para a atualidade. Em suma, como espero ter conseguido sugerir com a apresentação muito sumária dos textos selecionados, e como afirmam as organizadoras do livro, em Gilberto Freyre em quatro tempos, encontram-se tanto "um roteiro para novos leitores" quanto, para os "já iniciados", uma "aproximação original a temas e problemas já tantas vezes tratados, bem como a descoberta de novas perspectivas e frentes de reflexão" (p. 10).

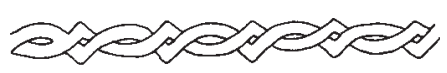

